\title{
Ocular manifestations of rheumatoid arthritis and their correlation with anti-cyclic citrullinated peptide antibodies
}

This article was published in the following Dove Press journal:

Clinical Ophthalmology

25 February 2015

Number of times this article has been viewed

\author{
Ammapati Paul Pandian \\ Vignesh \\ Renuka Srinivasan \\ Department of Ophthalmology, \\ Jawaharlal Institute of Postgraduate \\ Medical Education and Research, \\ Pondicherry, India
}

Purpose: To study the ocular manifestations of rheumatoid arthritis and to correlate the role of anti-cyclic citrullinated peptide antibody (anti-CCP antibody) with the ocular manifestations.

Methods: Three-hundred and ninety-two eyes of the 196 rheumatoid arthritis patients who attended the ophthalmology outpatient department underwent a detailed ocular examination using slit lamp biomicroscopy and ophthalmoscopy. The tear function of all the patients was assessed using Schirmer's test, tear film break-up time and ocular surface staining. The antiCCP antibody titers for all the rheumatoid arthritis patients were estimated using enzyme-linked immunosorbent assay tests.

Results: Seventy-seven patients (135 eyes, 39\%) out of the 196 patients studied had ocular manifestations typical of rheumatoid arthritis. Dry eye was the most common manifestation ( $28 \%, 54$ patients). Of the patients, $78 \%$ was females ( 60 patients). The mean duration of rheumatoid arthritis in patients with ocular manifestations was $5.4 \pm 2.7$ years and without ocular manifestations was 2.1 1 1.6years. Three percent of the patients had episcleritis (six patients). Scleritis was present in $2 \%$ of the patients (four patients). Peripheral ulcerative keratitis and sclerosing keratitis was present in $1 \%$ of the population each (two patients each). Eighty-five percent (66 patients) had bilateral manifestations $15 \%$ (eleven patients) had unilateral manifestations. There was a strong association between the presence of anti-CCP antibodies and ocular manifestations of rheumatoid arthritis which was shown by the statistically significant $P$-value of $<0.0001$.

Conclusion: Ocular manifestations are a significant part of the extra-articular manifestation of rheumatoid arthritis. Dry eye was the most common ocular manifestation. There was a statistically significant association between the presence of anti-CCP antibodies specific to rheumatoid arthritis and the ocular manifestations.

Keywords: rheumatoid arthritis, ocular manifestations, anti-CCP antibodies, dry eye, scleritis, peripheral ulcerative keratitis

\section{Introduction}

Rheumatoid arthritis (RA) is a chronic progressive, antibody mediated autoimmune disease that primarily affects small joints. It also involves other organs and ophthalmic involvement is often significant, causing varying degrees of ocular morbidity. Ocular manifestations of RA include dry eye, episcleritis, scleritis and peripheral ulcerative keratitis (PUK). ${ }^{1}$ Although rheumatoid factor (RF) is commonly used for diagnosis, anti-cyclic citrullinated peptide antibodies (anti-CCP antibodies) are a more sensitive and specific marker of systemic involvement in RA than rheumatoid factor antibody. Anti-CCP antibody is emerging as the preferred diagnostic marker for RA especially
Vignesh

Department of Ophthalmology, Jawaharlal Institute of Postgraduate Medical Education and Research,

12 Kamaraj Street, Tagore Nagar,

Pondicherry 605008, India

Tel +9l 9894910033

Email apvicky2010@gmail.com 
in early cases. It also predicts the future occurrence of the disease in undifferentiated arthritis. The sensitivity and specificity of anti-CCP reactivity for RA patients diagnosed based on American College of Rheumatology criteria were detected as $73.5 \%$ and $100 \%$, respectively which shows it to be a highly sensitive and specific marker for the disease. ${ }^{2}$ In this study we correlate the presence of ocular manifestations and the presence of anti-CCP antibodies.

\section{Methodology}

The study group consisted of 196 patients who presented for the first time to the outpatient clinic of the department of ophthalmology and immunology. The study was approved by the institute's ethics committee.

\section{Inclusion criteria}

All patients with RA undergoing routine ophthalmologic screening.

\section{Exclusion criteria}

1) Presence of other autoimmune systemic disorders like systemic lupus erythematosus, graft versus host disease, and any immunosuppressive disorders.

2) History of radiation.

3) Drug induced ocular manifestations which includes hydroxychloroquine induced maculopathy and other effects induced by chronic immunosuppression.

4) Age less than 18 years.

\section{Parameters studied in the patient}

The age, sex, and demographic data were initially collected from the patient. A detailed anterior segment examination using slit lamp was done to detect episcleritis, scleritis, and corneal changes. Dry eye examination was done using Schirmer's test, tear film break-up time, and ocular staining score. Fundus examination was done to detect any posterior segment manifestations. The anti-CCP antibody levels were detected using enzyme-linked immunosorbent assay (ELISA); and chi-square test was used to correlate their significance to ocular manifestations.

\section{Procedure}

Patients were subjected to a thorough clinical examination to confirm the diagnosis of arthritis. Erythrocyte sedimentation rate, auto-antibodies specific to RA, and X-rays were done in all patients. The anti-CCP antibody level was detected using ELISA test (DIASTAT; Axis-Shield Diagnostics Ltd., Dundee, Scotland, UK). Serum samples collected from patients were used for the ELISA test. A positive test was considered if levels were $\geq 5 \mathrm{U} / \mathrm{mL}^{2}{ }^{2}$ The diagnosis of RA was made based on the American Rheumatism Association 1987 revised criteria for the diagnosis of RA. ${ }^{3}$

History of the ocular symptoms was obtained and ocular examination was done in every patient with torch light and slit lamp biomicroscopy. Schirmer's test was done using Whatman filter paper and tear film break-up time was done using fluorescein stain in all patients to assess lacrimal function. Ocular surface involvement was assessed by fluorescein and Rose Bengal staining. The diagnosis of dry eye was based on the American-European Consensus Criteria for Sjögren's syndrome which includes the presence of a connective tissue disorder, duration of symptoms $>3$ months, tear film break-up time $<10$ seconds, Schirmer's test (without anesthesia) $\leq 5 \mathrm{~mm} / 5$ minutes, Van Bijsterveld score $\geq 4,{ }^{4}$ the diagnosis of scleritis, episcleritis and PUK is mainly clinical. Scleritis is painful chronic inflammation of sclera which may be associated with vision loss. Episcleritis is a benign, self-limiting condition of the outer coat covering the sclera. PUK is a form of ocular inflammation that involves the outer portions of the cornea associated with progressive thinning. Dilated retinal examination was done using direct and indirect ophthalmoscopy to detect any posterior segment changes.

\section{Observations}

\section{Age distribution}

One-hundred and ninety-six patients were studied, of these 77 (39\%) had ocular manifestations of RA. Most of the patients fell between $30-50$ years and the average age (mean \pm standard deviation) of the patients was 43.85 years \pm 21.54 (Table 1 and Figure 1).

\section{Sex distribution}

Of the total 196 patients studied, 150 (77\%) were females and $46(23 \%)$ were males. Among the 77 patients who had symptoms typical of RA, 60 (78\%) were females and 17 $(22 \%)$ were males.

Table I Age distribution in patients with ocular manifestations of rheumatoid arthritis

\begin{tabular}{lll}
\hline Age in years & Number of patients & Percentage \\
\hline $2 I-30$ & 7 & $9 \%$ \\
$3 I-40$ & 26 & $34 \%$ \\
$4 I-50$ & 28 & $37 \%$ \\
$5 I-60$ & 10 & $12 \%$ \\
$6 I-70$ & 6 & $8 \%$ \\
\hline
\end{tabular}




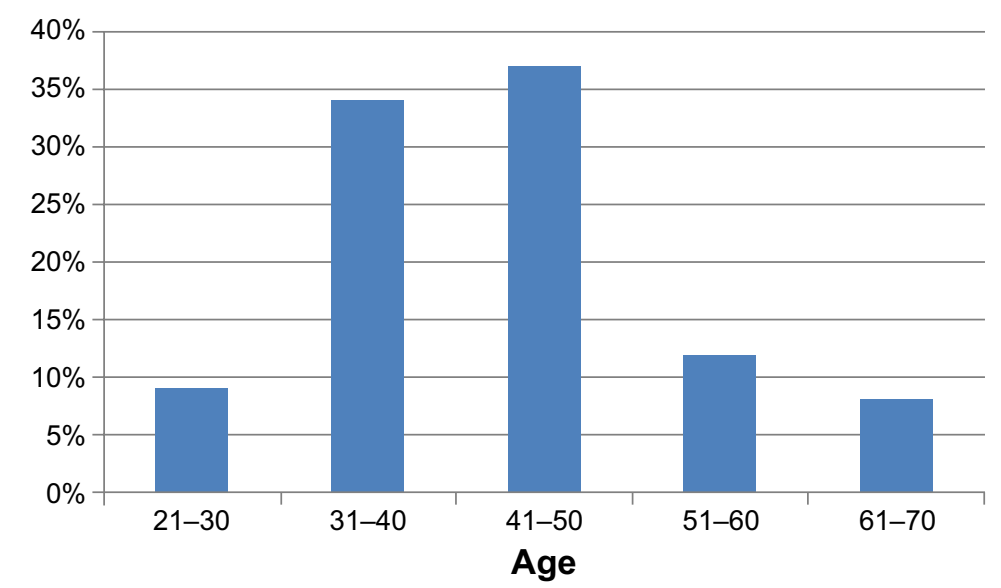

Figure I Age distribution in patients with ocular manifestations typical of rheumatoid arthritis.

\section{Duration of disease and incidence of ocular manifestations}

The mean (mean \pm standard deviation) duration of RA in patients with ocular manifestations was 5.4 \pm 2.7 years and without ocular manifestations was $2.1 \pm 1.6$ years.

The mean duration of RA among the patients with vision threatening complications like sclerosing keratitis and PUK was $10.5 \pm 3.1$ years.

\section{Ocular manifestations of RA}

Among the 196 patients included in the study 77 (39\%) had ocular manifestations typical of RA (Table 2 and Figure 2). Thirty percent (58 patients) of the patients were on immunosuppressive therapy for their systemic condition. Oral steroid was the main agent used. Around 5\% (nine patients) of the patients were on other immunosuppressive agents like hydroxychloroquine.

Table 2 Demographic data and ocular manifestations of rheumatoid arthritis

\begin{tabular}{|c|c|}
\hline \multirow[t]{3}{*}{ Age distribution } & $21-40$ years $-43 \%$ (33 patients) \\
\hline & $4 I-60$ years $-49 \%$ (38 patients) \\
\hline & $>60$ years $-8 \%$ ( 6 patients $)$ \\
\hline \multirow[t]{2}{*}{ Sex } & 60 patients $(78 \%)$ - females \\
\hline & 17 patients $(22 \%)-$ males \\
\hline \multirow[t]{2}{*}{ Duration of illness } & Mean duration with ocular manifestations $-5.4 \pm 2.7$ years \\
\hline & Mean duration without ocular manifestations $-2.1 \pm \mathrm{I} .6$ years \\
\hline \multirow[t]{7}{*}{ Ocular manifestations } & Dry eye $28 \%$ (54 patients) \\
\hline & Filamentary keratitis 3\% (6 patients) \\
\hline & Episcleritis $3 \%$ (6 patients) \\
\hline & Peripheral keratitis I\% (2 patients) \\
\hline & Sclerosing keratitis I\% (2 patients) \\
\hline & Scleritis $2 \%$ (4 patients) \\
\hline & Cataract I\% (3 patients) \\
\hline \multirow[t]{4}{*}{ Number of eyes involved } & 392 eyes 196 patients were studied \\
\hline & $85 \%$ patients had bilateral manifestations \\
\hline & I5\% patients had unilateral manifestations \\
\hline & Total number of eyes with ocular manifestations -135 \\
\hline \multirow[t]{2}{*}{ Schirmer's test } & Mean value in patients with manifestations $-4.2 \pm 0.7 \mathrm{~mm}$ \\
\hline & Mean value in patients without manifestations $-12.34 \pm 2.5 \mathrm{~mm}$ \\
\hline \multirow[t]{2}{*}{ TBUT value } & Mean value in patients with manifestations $-7.7 \pm 2.1$ secs \\
\hline & Mean value in patients without manifestations $-14.1 \pm 2.6$ secs \\
\hline \multirow[t]{2}{*}{ Ocular staining score } & Average score in patients with manifestations $-5.5 \pm 1.2$ \\
\hline & Average score in patients without manifestations $-2.5 \pm 1.5$ \\
\hline \multirow[t]{2}{*}{ Visual acuity } & $86 \%$ (67 patients) has a vision of $20 / 20$ \\
\hline & $14 \%$ (I0 patients) had vision loss \\
\hline
\end{tabular}

Abbreviations: secs, seconds; TBUT, tear film break-up time. 


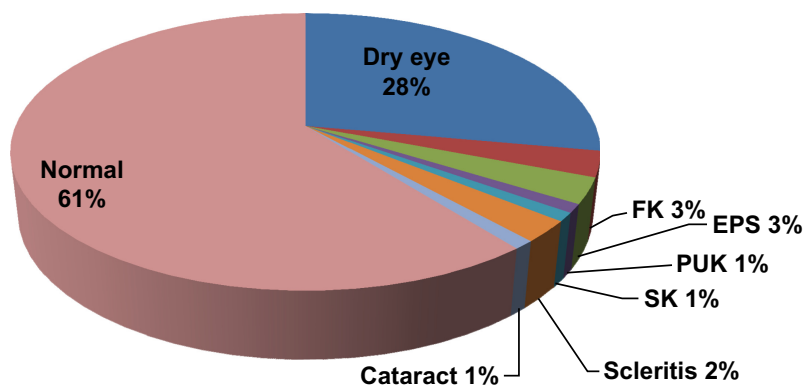

Figure 2 Percentage distribution of ocular manifestations of rheumatoid arthritis among the total study population.

Abbreviations: FK, filamentary keratitis; EPS, episcleritis; SK, sclerosing keratitis; PUK, peripheral ulcerative keratitis.

\section{Laterality}

Eighty-five percent (66 patients) of the manifestations was bilateral and only $15 \%$ (eleven patients) was unilateral which mostly included scleritis, episcleritis, and PUK.

\section{Patients with more than one manifestation}

Eighty percent (62 patients) of the patients with ocular involvement had only one manifestation. The remaining $20 \%$ (15 patients) had more than one manifestation which mainly included one of the vision threatening manifestations with associated dry eye or cataract.

\section{Visual acuity in patients with ocular manifestations of RA}

Eighty-six percent (67 patients) of the patients had normal visual acuity. Fourteen percent (ten patients) of the patients had decreased visual acuity due to manifestations like PUK, sclerosing keratitis, and scleritis and cataract.

\section{Role of anti-CCP antibodies and ocular symptoms typical of RA}

Chi-square test was used to analyze the results. The twosided $P$-value is $<0.0001$, considered extremely significant. Odds ratio $=4.168$. Ninety-five percent confidence interval: 2.256 to 7.698 . Hence there is a strong association between the presence of anti-CCP antibodies and ocular manifestations of RA (Table 3).

\section{Discussion}

Ocular manifestations were found in 77 of the 196 patients studied which is $39 \%$ of the study population. Reddy et al in their study also found the incidence of ocular manifestations in RA to be $39 \%$ in a population of 100 patients. ${ }^{5}$ This study indicates that ocular involvement is fairly common and the need for close follow-up. The rheumatologists should get an ocular examination done for all patients at diagnosis and then at periodic intervals for early detection of any ocular involvement. Punjabi et al reported that $27.3 \%$ of RA patients had dry eye in an Indian population. ${ }^{6}$ Bettero et al reported secondary Sjögren's syndrome in $12.1 \%$ of the population with RA. ${ }^{7}$ In the present study the prevalence of dry eye was $28 \%$ and was the most common manifestation of RA. These results were similar to the previous studies mentioned above. The diagnosis of secondary Sjögren's was made based on the AmericanEuropean Consensus Criteria for Sjögren's syndrome which was based on the duration of symptoms, Schirmer's test, and positive vital dye staining of the eye surface. Tear film osmolarity also correlates with dry eye activity. Tong et al found in a recent study that tear film osmolarity correlated with the dry eye severity score. ${ }^{8}$ All this suggests that more research is needed on the markers of ocular surface in RA. Tong et al studied the immune factors that lead to dry eye and correlated them with systemic disease which could lead to potential treatment targets in the future showing the importance of conducting further studies on the ocular surface in RA patients. ${ }^{8}$ Villani et al studied the effect of immunosuppression on the ocular surface via confocal microscopy and cytokines level and found that immunosuppression modified the ocular surface pathology in RA patients with secondary Sjögren's syndrome. ${ }^{9}$ Villani et al studied the corneal involvement in RA by confocal microscopy and found the corneal surface activity was more in patients with secondary Sjögren's. ${ }^{10}$ The ocular manifestations were more common with prolonged duration of the disease. The severity was also worse with longer duration of the disease. McGavin et al studied 4,210 patients with RA and established the incidence of episcleritis as $0.17 \% .{ }^{11}$ Bhadoria et al reported episcleritis in $0.93 \%$ of the patients of the study population. ${ }^{12}$ In the present study we found episcleritis in 3\% of the RA patients which is slightly higher than the above

Table 3 Role of anti-CCP antibodies and ocular symptoms typical of rheumatoid arthritis

\begin{tabular}{llll}
\hline $\begin{array}{l}\text { Auto-antibodies } \\
\text { (RA factor/anti-CCP) }\end{array}$ & $\begin{array}{l}\text { Ocular manifestations } \\
\text { present }\end{array}$ & $\begin{array}{l}\text { Ocular manifestations } \\
\text { absent }\end{array}$ & Total \\
\hline Present & 45 & 31 & 76 \\
Absent & 32 & 88 & 120 \\
Total & 77 & 119 & 196 \\
\hline
\end{tabular}

Abbreviations: anti-CCP antibodies, anti-cyclic citrullinated peptide antibodies; RA, rheumatoid arthritis. 
mentioned studies. Half of the patients with episcleritis had associated dry eye. In our study the vision threatening complications were scleritis, sclerosing keratitis, and PUK which affected $14 \%$ of the study population. All the patients with vision threatening complications were positive for anti-CCP antibodies. McGavin et al reported the incidence of scleritis as $0.67 \%$ in RA patients. ${ }^{11}$ In the present study scleritis was found in $2 \%$ (four patients) of the study population out of which one case was nodular scleritis and the rest were diffuse scleritis which was comparable to the previous studies. Squirrell et al reviewed the clinical and serological characteristics of the arthritis at the time of presentation of PUK. All patients had a long history of high-titer seropositive, nodular, erosive RA which on presentation of PUK had been quiescent or well controlled for many years. ${ }^{13}$ In our study the mean duration of RA among the patients with vision threatening complications like sclerosing keratitis and PUK was 10.5 years which was comparable to the abovementioned studies in which the vision threatening complications were associated with longer duration of the disease. Bettero et al reported ulcerative keratitis in $2 \%$ of the study population. ${ }^{7}$ In our study both sclerosing keratitis and PUK were found in $1 \%$ of the study population. All the patients had a long history of RA. Among the two patients with sclerosing keratitis one patient had unilateral involvement and only mild impairment of vision. Another patient with sclerosing keratitis had bilateral involvement with vision of 20/200 with associated severe dry eye. Anti-CCP antibodies are a more sensitive and specific marker of RA. Itty et al in their study found that the combined presence of anti-CCP antibodies and RA factor had more severe ocular involvement compared to those who were negative for these antibodies. ${ }^{1}$ In the present study there was a strong association between the presence of anti-CCP antibodies and the presence of ocular manifestations of RA. This will help in early detection of ocular manifestations of RA which needs corroboration by longitudinal studies.

\section{Conclusion}

Ocular manifestations are a significant part of the extraarticular manifestation of RA. Dry eye was the most common ocular manifestation. There was a significant association between the duration of the disease and ocular manifestations. The longer the duration, more common and severe are the ocular manifestations. There was a statistically significant association between the presence of anti-CCP antibodies related to RA and the ocular manifestations.

\section{Disclosure}

The authors have no conflicts of interest to disclose.

\section{References}

1. Itty S, Pulido JS, Bakri SJ, Baratz KH, Matteson EL, Hodge DO Anti-Cyclic Citrullinated Peptide, Rheumatoid Factor, and Ocular Symptoms Typical of Rheumatoid Arthritis. Trans Am Ophthalmol Soc. 2008;106:75-81.

2. El-Banna H, Jiman-Fatani A. Anti-cyclic citrullinated peptide antibodies and paraoxonase-1 polymorphism in rheumatoid arthritis. $B M C$ Musculoskelet Disord. 2014;15:379.

3. Arnett FC, Edworthy SM, Bloch DA, et al. The American Rheumatism Association 1987 revised criteria for the classification of rheumatoid arthritis. Arthritis Rheum. 1988;31(3):315-324.

4. Vitali C, Bombardieri S, Jonsson R, et al. Classification criteria for Sjögren's syndrome: a revised version of the European criteria proposed by the American-European Consensus Group. Ann Rheum Dis. 2002; 61(6):554-558.

5. Reddy SC, Gupta SD, Jain IS, Deodhar SD. Ocular manifestations of rheumatoid arthritis. Indian J Ophthalmol. 1977;25(3):20-26.

6. Punjabi OS, Adyanthaya RS, Mhatre AD, Jehangir RP. Rheumatoid arthritis is a risk factor for dry eye in the Indian population. Ophthalmic Epidemiol. 2006;13(6):379-384.

7. Bettero RG, Cebrian RFM, Skare TL. [Prevalence of ocular manifestation in 198 patients with rheumatoid arthritis: a retrospective study] Arq Bras Oftalmol. 2008;71(3):365-369. Portuguese.

8. Tong L, Thumboo J, Tan YK, Wong TY, Albani S. The eye: a window of opportunity in rheumatoid arthritis? Nat Rev Rheumatol. 2014;10(9): 552-560.

9. Villani E, Galimberti D, Del Papa N, Nucci P, Ratiglia R. Inflammation in dry eye associated with rheumatoid arthritis: cytokine and in vivo confocal microscopy study. Innate Immun. 2013;19(4):420-427.

10. Villani E, Galimberti D, Viola F, Mapelli C, Papa ND, Ratiglia R. Corneal Involvement in Rheumatoid Arthritis: An In Vivo Confocal Study. Invest Ophthalmol Vis Sci. 2008;49(2):560-564.

11. McGavin DD, Williamson J, Forrester JV, et al. Episcleritis and scleritis. A study of their clinical manifestations and association with rheumatoid arthritis. Br J Ophthalmol. 1976;60(3):192-226.

12. Bhadoria DP, Bhadoria P, Sundaram KR, Panda A, Malaviya AN. Ocular manifestations of rheumatoid arthritis. J Indian Med Assoc. 1989; 87(6):134-135.

13. Squirrell DM, Winfield J, Amos RS. Peripheral ulcerative keratitis "corneal melt" and rheumatoid arthritis: a case series. Rheumatol (Oxford). 1999;38(12):1245-1248.
Clinical Ophthalmology

\section{Publish your work in this journal}

Clinical Ophthalmology is an international, peer-reviewed journal covering all subspecialties within ophthalmology. Key topics include: Optometry; Visual science; Pharmacology and drug therapy in eye diseases; Basic Sciences; Primary and Secondary eye care; Patient Safety and Quality of Care Improvements. This journal is indexed on Submit your manuscript here: http://www.dovepress.com/clinical-ophthalmology-journal
Dovepress

PubMed Central and CAS, and is the official journal of The Society of Clinical Ophthalmology (SCO). The manuscript management system is completely online and includes a very quick and fair peer-review system, which is all easy to use. Visit http://www.dovepress.com/ testimonials.php to read real quotes from published authors. 